\title{
Silk Threading-A New Revolutionary Jewellery from India
}

\author{
S SreeLekha Surendran* \\ Freelance Entrepreneur, S-Collections, India \\ Received: 阱 March 08, 2018; Published: 制April 05, 2018 \\ *Corresponding author: S. SreeLekha Surendran, Freelance Entrepreneur, S-Collections, Tel: +91 9620409339; \\ Email: lekhamoorthy26@gmail.com
}

\section{Short Communication}

Jewellery is a mesmerizing term which any feminine gender would love to admire and afford. Instantly, this magic term recalls about ornaments made up of gold, silver, platinum etc., in our minds. But the 21st century scenario is very different where the word jewellery has a different connotation. In the recent years, may be women would have felt jaded of using the above mentioned ornaments which led to a change in artificial jewellery. Popularly termed as funky, imitation, bling, modern or fashion etc., are the new terms and the current trends go on. Though, such discernments are stated to revelation on the social status, invariably such artificial jewellery is worn right from the poor to the rich. No doubt that so called artificial jewellery has made a mini industrial revolution among the metropolitan women who are supposed to admire such antiques wearables from head-to-toe $[1,2]$.

\section{Artificial Jewellery}

Indian Jewellery is legendary all over the world as they are royal inspired by the old Indian tradition and is considered to be one of the oldest ways to flaunt women's beauty. Today in India where real Jewellery has become extremely expensive and trend setting is moving towards imitation Jewellery. These are only look alike real Jewellery but are much economical and affordable to common Indian women. Conversely with artificial Jewellery, it is more convenient to innovate multiple and numerous designs and ideas than the regular Jewellery designs. Also, it is not an unacceptable fact that these do not have good appreciable deterioration unlike the other ones.

\section{Silk-Threading}

Commercial silks originate from reared silkworm pupae that square measure bred to provide a white coloured silk thread with no mineral on the surface. The pupae square measure killed by either dipping them in boiling water before the adult moths emerge or by piercing them with a needle. These factors all contribute to the flexibility of the entire cocoon to be unravelled joined continuous thread, allowing a far stronger artefact to be plain-woven from the silk. Wild silks additionally tend to be tougher to die than silk from the cultivated silkworm. A way called demineralising permits the mineral layer round the cocoon to be removed, deed solely variability in colour as a barrier from making an ad silk trade supported wild silks in components of the planet wherever wild silk moths thrive, like continent and South America. The entire production method of silk is divided into many steps that square measure generally handled by totally different entities (Figure 2).

\section{Silk-Threaded Jewellery}

The typical groundwork on the silk threading artificial Jewellery starts from simply covering an acrylic or plastic ornamental material with such threads. The artistic skill set starts here at the precision and accuracy of the cover over such ornaments. Innovation and designs goes unlimited by use of various colours and mixing it with warp ribbing, crossing over, stretching, bending, overlapping, etc. Further, creativity adds up with attachment of artificial stones over it which may add blink to the jewel. Beads which are made of glass, gemstones, metal, wood, shells, clay and polymer clay etc., are most commonly used in encompassing necklaces, bracelets, earrings, belts and rings. The use of seed beads is an embroidery technique where seed beads are sewn onto fabric backings to create broad collar neck pieces and beaded bracelets. Bead embroidery, a popular type of handwork during the Victorian era, is enjoying a renaissance in modern Jewellery making. Beading, or beadwork, is also very popular in many African and indigenous North American cultures.

\section{Designs}

A tentative design with patterns are listed as below for the readers reference.

\section{a) Goddess-Lakshmi}

Neckpiece with Pink \& Green Silk Thread beads embellished with spacers \& antique connecter \& Beautiful Antique Lakshmi 
Pendent. Green Silk threads Jumukas \& pink Silk Thread beads Embellished with golden ball chain paired up with beautiful antique Lakshmi studs. Nakshatra Bangles as side bangles with green \& pink mix Bangles makes the set grand \& elegant (Figure 1).

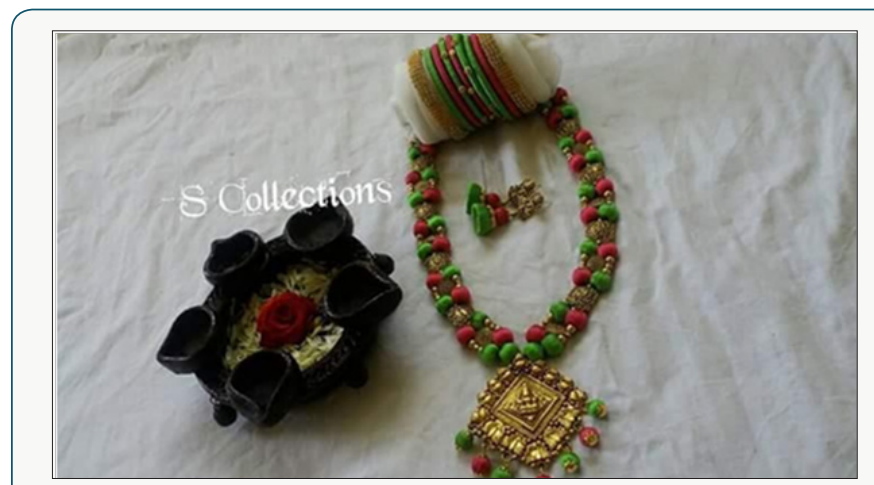

Figure 1: Goddess-Lakshmi.

\section{b) Lorials Set}

Beautiful Neckpiece is made of pink silk thread beads with Lorials pearl with Medium Pink Jumukas embellished with pearl chains \& golden chains paired up with antique dancing small peacock studs. A set of elegant bangles with double design pattern worked with pearl \& stone. Matching Tic Tac hair clips embellished with pearl \& stone work (Figure 2).

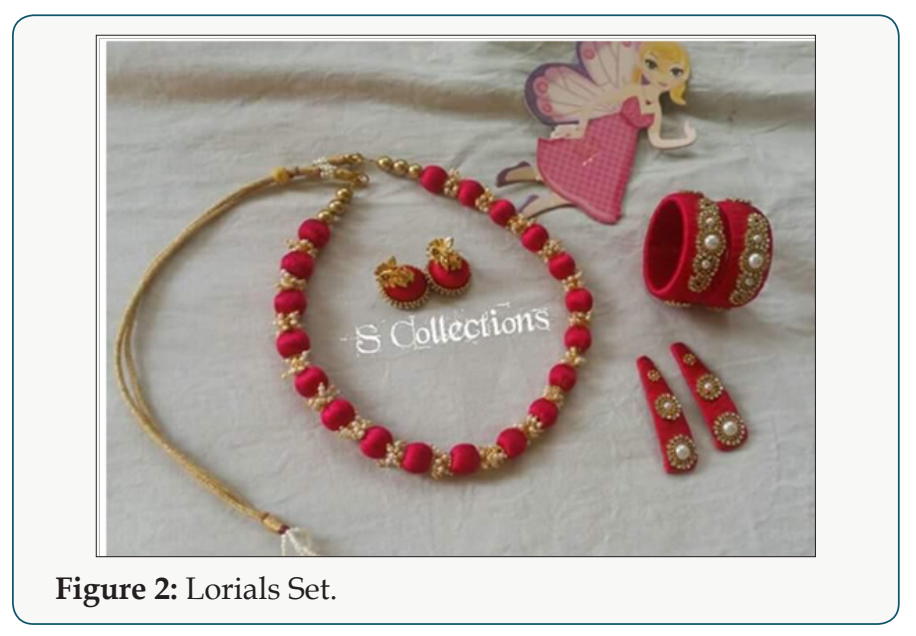

\section{c) Peacock Set}

Large peacock blue Jhumkas embellished with golden beads packed up with peacock studs. Neck piece with silk thread beads and antique peacock pendant matching the stud which is embellished with golden kundans. A set of simple elegant bangles with crisscross design stoned in on the outer layer (Figure 3).

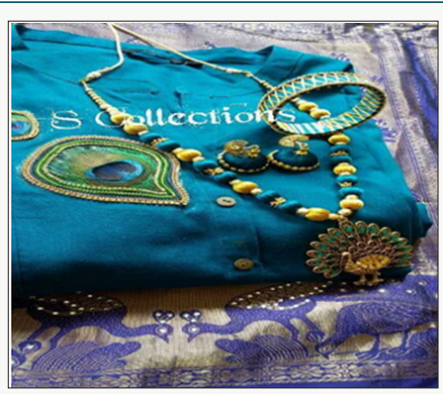

Figure 3: Peacock Set.

\section{Developments}

The targeted market is obviously on typical Indian ladies and hence, metropolitan hunt is continual across online and social media. Numerous FB and twitter follow-ups are common happenings on the internet users. Online Jewellery entrepreneur's viz., caratlane, bluestone etc., are troubled that needless to mention on the typical Indian hesitation on investing for purchasing it without having a visual of it. However, as economical and affordable artificial Jewellery to a common Indian girl, this silk threading is no doubt an emerging revolution feasible by any innovators and creative human beings.

\section{Acknowledgement}

The author is one such innovator in home-made silk threaded Jewellery famed in the social media. Readers are advised to check the references for further reading.

\section{References}

1. Borel F (1994) The Splendour of Ethnic Jewellery: from the Colette and Jean-Pierre Ghysels Collection.

2. LaGamma, Alisa (1991) Metropolitan jewellery. The Metropolitan Museum of Art, New York, USA.

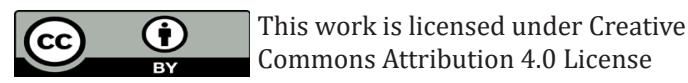

To Submit Your Article Click Here:

Submit Article

DOI: $10.32474 /$ LTTFD.2018.01.000123

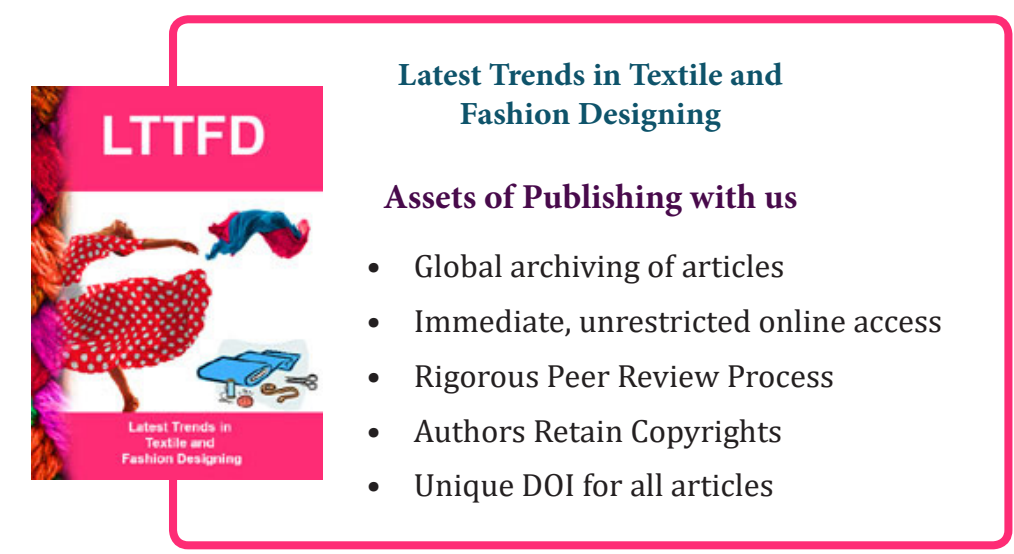

